\title{
Microemulsion synthesis of Copper Oxide nanorod-like structures
}

D. Dodoo-Arhin ${ }^{* 1,2}$, M. Leoni ${ }^{3}$ and P. Scardi ${ }^{3}$.

${ }^{1}$ Department of Materials Science and Engineering, University of Ghana, Accra, Ghana.

${ }^{2}$ Department of Physics, Institute of Applied Materials, University of Pretoria, Pretoria 0002, South Africa.

${ }^{3}$ Department of Materials Engineering and Industrial Technologies, University of Trento, via Mesiano, 77 - 38100 Trento (Italy)

Corresponding author: David Dodoo-Arhin,dodooa@ing.unitn.it,ddarhin@yahoo.com

\begin{abstract}
Copper oxide $(\mathrm{CuO})$ nanorod-like structures made of spherical nanocrystals were synthesized at moderate temperature $\left(80^{\circ} \mathrm{C}\right)$ starting from $\mathrm{CuCl}_{2} \cdot 2 \mathrm{H}_{2} \mathrm{O}$ crystals in a water/n-heptane microemulsion stabilised by the nonionic Brij-30 surfactant. Whole Powder Pattern Modelling of the X-ray diffraction pattern shows absence of linear and planar defects with crystalline domains in the range of $4-8 \mathrm{~nm}$. A linear correlation between the average size of the particles and the quantity of water in the system was observed: all synthesised specimens show a large blue shift of the energy bandgap (up to $2.7 \mathrm{eV}$ versus $1.2 \mathrm{eV}$ of bulk $\mathrm{CuO}$ ) resulting from quantum confinement effects. The mechanism of growth of the spherical nanoparticles into nanorod-like structures has been elucidated.
\end{abstract}

Keywords: Microemulsion; $\mathrm{CuO}$; X-ray diffraction; Electron microscopy; nanostructured materials; grain growth. 


\section{INTRODUCTION}

Nanostructured semiconductor materials have stimulated intensive research interest in the recent years due to their unique properties (different from the bulk ones) and the potential applications in photonic and nanoelectronics [1-3]. Synthetic 1-dimensional nanostructures such as e.g. quantum dots, nanorods or nanotubes, are ideal systems for the study of dimensional and morphological dependence of optical, electrical and mechanical properties of final materials [4]. It is believed that nanostructures with dimensions of a few nanometers will have novel and unique physical and chemical properties due to quantum confinement effects.

High-temperature superconductivity in materials such as copper oxide perovskites $[5,6]$, has been attributed to a Jahn-Teller distortion in a highly symmetric divalent copper monoxide structure which introduces a strong electron-phonon interaction leading to the superconductivity. The need to understand the origin and mechanism of this phenomenon has led to extensive studies of simple and complex copper oxides [7-9]

Monoclinic cupric oxide $\mathrm{CuO}$ (tenorite, space group $\mathrm{C} 2 / \mathrm{c}, \mathrm{a}=4.6850 \AA$, b $=3.4230 \AA, \mathrm{c}=5.1320 \AA$, $\beta=99.52^{\circ}$, ICDD PDF card \# 72-0629) is an important p-type transition metal oxide. The material is a direct bandgap semiconductor. It couples a narrow band gap $(\mathrm{Eg}=1.2 \mathrm{eV}-1.8 \mathrm{eV})[10-12]$ with a set of properties such as high-temperature superconductivity and good photoconductivity and photochemical properties [13]. This largely explains the growth of applications in the last years in the more diverse fields such as solar cells [14], gas sensors [15], field emission (FE) emitters [16], and lithium ion battery electrode materials [17].

The structure of $\mathrm{CuO}$ is certainly an exception in the periodic table [18]: all neighbouring oxides (from $\mathrm{MnO}$ to $\mathrm{NiO}$ ), in fact, show the cubic rocksalt structure and are correlated antiferromagnetic (AFM) insulators [19-22]. Cupric oxide, on the contrary, is monoclinic, ferroelectric [18] and recent studies seem to indicate it possesses at least three different magnetic polymorphs [23, 24].

Size and morphology of copper oxide particles have a strong effect on the optical, semiconducting, and piezoelectric properties of the material. To investigate for those effects and for possible applications, nanostructured copper oxides have been synthesised in several shapes such as 
nanobelts [25], nanorods [26], nanowires [27], and nanoribbons [28]. Several techniques, ranging from reverse micelles microemulsions [29], electrochemical and sonochemical deposition [30, 31], chemical vapour deposition [32], alcoho-thermal and hydrothermal synthesis [33, 34], thermal decomposition [35] and high-temperature synthesis [36] are available to produce such non-equilibrium morphologies. Self-assembly (e.g. reverse micelle microemulsions) driven e.g. by surface tension, capillary effects, electric and magnetic forces, and hydrophobic interactions, is an effective strategy for forming a wide variety of motifs, otherwise impossible to form under equilibrium conditions [34, 37, 38]. However, precise control over nanocrystalline $\mathrm{CuO}$ synthesis remains a big challenge.

The availability of good techniques for the measurement of size and size distribution of crystalline domains is also a critical factor. Techniques such as TEM and XRD Line Profile Analysis usually provide information only about the average particle size (e.g. Scherrer formula [39] and WilliamsonHall plot [40]) or are limited to the analysis of a small number of particles (TEM). Moreover, TEM analysis may suffer of systematic errors caused by the specimen preparation and by the presence of extensive agglomeration of nanoparticles. The Whole Powder Pattern Modelling (WPPM) of X-ray diffraction data is a possible solution, being at the same time statistically valid (millions of particles sampled), relatively unaffected by specimen preparation issues, and user-independent. The technique provides a complete microstructural information on nano-scale powders based on the direct refinement of physical models on the experimental data, with no arbitrary assumptions on the peak profiles.

In this paper, we present results of a thermally mediated single reverse micelle microemulsion method for the preparation of nanorods-like $\mathrm{CuO}$ nanocrystals. The analysis of the crystals reveals some insights on the possibility of self assembly of spherical particles into long chains, imparting an overall rod-like shape to the particles.

\section{EXPERIMENTAL}

\subsection{Materials and specimens}

A stable reverse micelle microemulsion was prepared by mixing a non-ionic surfactant (Polyoxyethylene 4 Lauryl Ether $\left(\mathrm{C}_{2} \mathrm{H}_{4} \mathrm{O}\right)_{n} \mathrm{C}_{12} \mathrm{H}_{26} \mathrm{O}, \mathrm{n} \approx 4$, - $\mathrm{Brij}$ 30) and oil (n-heptane) and then subsequently adding deionised water $(<1.8 \mu \mathrm{S} / \mathrm{cm})$. Batches of $20 \mathrm{ml}$ were made by adding a fixed 
volume (16.54 \%) of surfactant (Brij 30, Sigma Aldrich 98\% purity) to n-heptane (Sigma Aldrich, 99\% purity) and further adding a varying content of deionised water (1-5\%). The surfactant concentration has been chosen to ensure a stable microemulsion as observed in the literature [41, 42, 43]. Table 1 identifies the various batches and the corresponding specimens. Each batch was produced at least 3 times to guarantee the reproducibility of the result.

An aliquot of $25 \mathrm{mg}$ of $\mathrm{CuCl}_{2} \cdot 2 \mathrm{H}_{2} \mathrm{O}$ (Sigma Aldrich, 6174-250GF) crystals was added to each microemulsion and left under magnetic stirring for 10 mins until a sky blue transparent mixture was obtained. 50mg of $\mathrm{NaOH}$ crystals were then dissolved into the mixture under constant stirring for about 15 mins. A deep blue microemulsion was obtained without precipitation.

The mixture was then heated at $80^{\circ} \mathrm{C}$ and kept under gentle stirring at $20 \mathrm{rpm}$ for 4 hours. The mixture gradually changed from deep blue to greenish-blue then to dark brown. The so-formed sol was allowed to cool to room temperature and then added $10 \mathrm{ml}$ acetone (Sigma Aldrich 99\% purity) to break the microemulsion.

Particles were subsequently washed with $10 \mathrm{ml}$ ethanol and $20 \mathrm{ml}$ deionised water. For a faster and effective collection, the solution was centrifuged four times at $6000 \mathrm{rpm}$ for 5 mins. No macroscopic agglomeration was observed. Powders were dried at $\approx 100^{\circ} \mathrm{C}$ on (h00) Si wafer for XRD analysis.

\subsection{Characterisation techniques}

X-ray powder diffraction (XRD) patterns were collected on a Rigaku 3D-max Bragg-Brentano diffractometer operating with a copper tube ( $\mathrm{Cu} \mathrm{K} \alpha$ radiation) at $40 \mathrm{kV}$ and $30 \mathrm{~mA}$. The goniometer is equipped with a curved-crystal graphite analyser in the diffracted beam, providing a symmetrical instrumental profile over the investigated range.

Data for all specimens were recorded in the $30-70^{\circ} 2 \theta$ range with a step size of $0.1^{\circ}$ and a counting time of 20 s per step. Data were analysed using the Whole Powder Pattern Modelling (WPPM) method [44] implemented in the PM2K software [45]. The instrumental resolution function was characterised 
with the NIST SRM 660a (LaB6) standard [46, 45]: all peak profiles of the LaB6 phase were simultaneously fitted with symmetrical pseudo-Voigt functions whose width and shape were constrained according to the Caglioti et al. formulae [47].

Transmission electron microscopy was performed on a Philips EM400T electron microscope operated at $120 \mathrm{kV}$ and providing a maximum resolution of $3.0 \AA$.

Transmission FTIR spectra were recorded on a Nicolet Avatar 550 (Thermo Optics Electron Corporation, Waltham, MA) instrument in the $4000-400 \mathrm{~cm}^{-1}$ range with $2 \mathrm{~cm}^{-1}$ resolution; the Spectrum v5.3.0 software was employed for the FTIR analysis.

UV-Vis-NIR was performed on a Varian Cary 5000 spectrophotometer in the range of 300 $850 \mathrm{~nm}$ based on an R928 (PMT) detector with a resolution of $2 \mathrm{~nm}$.

\section{RESULTS AND DISCUSSION}

\subsection{Synthesis}

In aqueous solution, $\mathrm{CuCl}_{2} \cdot 2 \mathrm{H}_{2} \mathrm{O}$ dissociates into $\left[\mathrm{Cu}\left(\mathrm{H}_{2} \mathrm{O}\right)_{6}\right]^{2+}$ ions (responsible for the sky blue colouring) and $\mathrm{Cl}^{-}$anions. Coordination of $\mathrm{Cl}^{-}$with other Copper ions may partially occur. In the $\left[\mathrm{Cu}\left(\mathrm{H}_{2} \mathrm{O}\right)_{6}\right]^{2+}$ structure, six water molecules completely surround each $\mathrm{Cu}^{2+}$ ion, shielding it. Due to the solvating action when copper salt is dissolved in water, four water molecules surround the $\mathrm{Cu}^{2+}$ to form a square structure $\left(\mathrm{Cu}(\mathrm{OH})_{4}{ }^{2-}\right)$, and the other two water molecules locate at its axis. According to the anionic coordination polyhedra theoretical model [48-52], cations exist in the form of complexes whose ligands are $\mathrm{OH}^{-}$ions in an aqueous solution: the complex whose coordination numbers are equal to that of the crystal formed is called a growth unit. Moreover, the formation of growth units and the incorporation of the growth units into the crystal nucleus are induced by a dehydration reaction. Accordingly, the growth units for $\mathrm{CuO}$ nanocrystals are considered to be $\mathrm{Cu}(\mathrm{OH})_{6}{ }^{4-}$, a coordinating octahedron in the $\mathrm{NaOH}$ solution. In this case, four $\mathrm{OH}^{-}$ions are arranged on a planar square, and the other two $\mathrm{OH}^{-}$ions are located on a perpendicular axis. 
The binding energies of the two $\mathrm{OH}$ - ions located on the octahedron axis are lower than those of $\mathrm{OH}-$ located on the plane [14]. This means that the two $\mathrm{OH}^{-}$ions located at the axis are easily replaced and dehydrated to form $\mathrm{CuO}$ nanocrystallites, so that the growth rate along the axes is higher than in the plane. The growth mechanism and formation of different shapes of $\mathrm{CuO}$ nanocrystals (e.g. nanorods, nanobelts, nanowires, etc) can be explained with this difference in growth rates along various directions. The reaction temperature can play an important role there. More in detail, the reactions leading to the formation of $\mathrm{CuO}$ can be summarised into:

$$
\begin{aligned}
& \mathrm{CuCl}_{2}(\mathrm{aq})+2 \mathrm{NaOH}(\mathrm{aq}) \longrightarrow \mathrm{Cu}(\mathrm{OH})_{2}(\mathrm{aq})+2 \mathrm{NaCl}(\mathrm{aq}) \\
& \mathrm{Cu}(\mathrm{OH})_{2}(\mathrm{aq})+2 \mathrm{OH}^{-}(\mathrm{aq}) \longrightarrow\left[\mathrm{Cu}(\mathrm{OH})_{4}\right]^{2-}(\mathrm{aq}) \\
& {\left[\mathrm{Cu}(\mathrm{OH})_{4}\right]^{2-}(\mathrm{aq}) \stackrel{\text { heat }}{\longrightarrow} \mathrm{CuO}_{(\mathrm{s})}+2 \mathrm{OH}^{-}(\mathrm{aq})+\mathrm{H}_{2} \mathrm{O}}
\end{aligned}
$$

At low temperatures, the hydroxyl groups of the $\mathrm{Cu}(\mathrm{OH})_{6}{ }^{4-}$ complex (produced on addition of $\mathrm{NaOH}$ ) might form hydrogen bonds by interconnection: the directional growth would then be inhibited, leading to the formation of irregularly shaped nanocrystals [53-55]. At higher temperatures close to room temperature $\left(\mathrm{T} \leq 25{ }^{\circ} \mathrm{C}\right)$ - only small quantities of hydrogen bonds are destroyed. The residual hydrogen bonds may still lead to the formation of structures with mixed morphologies. When the reaction temperature is increased $\left(25^{\circ} \mathrm{C}<\mathrm{T}<100{ }^{\circ} \mathrm{C}\right)$, there is a corresponding increase in the nucleation and growth rates as well as the destruction of more hydrogen bonds. In our case, the reaction temperature has been chosen to be $80^{\circ} \mathrm{C}$ to prevent evaporation of the water and to be lower than the breaking point temperature of the surfactant. Further investigation on the effect of reaction temperature and time on the particle size, size distribution, morphology and the surfactant breaking point boundary conditions of the Brij 30 microemulsion will lead to a better understanding of the growth mechanism of the as-produced $\mathrm{CuO}$ nanostructures.

In the synthesis, reactions (1.1) and (1.2) take place within reverse micelles of the microemulsion. The microemulsion droplets (reverse micelles) act as the nanoreactors to produce the dissolved $\mathrm{Cu}(\mathrm{OH})_{2}$ nanocrystals. Based on its structural features and specific interactions of the $\mathrm{Cu}^{2+}$ 
ions with ligands in the solution, $\mathrm{Cu}(\mathrm{OH})_{2}$ tends to form a wire-like structure. This structure has been determined to consist of oblate chains of $\mathrm{Cu}(\mathrm{OH})_{2}$ in the (001) planes and oriented along the [100] direction: a feature characteristic of the square-planar coordinated $\mathrm{Cu}^{2+}$ ions [56].

The surfactant molecules adhere to the surface of nanoparticles which serve as a protective layer to prevent the fusion of the droplets as a result of collisions $[57,58]$.

There are two important factors that affect the exchange rate of reverse micelles in microemulsion, namely, the dimer stability and the size of channels between the dimers [59]. The dimer stability, which depends on the intermicellar attractive potential, determines the interdroplet transfer of reactants. On the other hand, the size of channels, which depends on the rigidity of interfacial film in the microemulsion, determines the Ostwald ripening contribution. At lower water content, the interfacial film is more rigid since it is closely surrounded by the surfactant molecules. Hence, the fused dimers formed through droplets collision can disappear rapidly since the film stability is high, and channel for the exchange of reactants is narrower. This results in relatively smaller particle size and narrower size distribution of the resulting nanocrystals [7].

When the water content is increased, there are more free water molecules in the microemulsion and the interfacial rigidity is reduced as compared with that at lower water content.

\subsection{X-ray diffraction analysis and transmission electron microscopy}

The XRD patterns (Figure 1) show a predominant presence of $\mathrm{CuO}$ with traces of $\mathrm{Cu}(\mathrm{OH})_{2}$.under the tails of the peaks. This can be a consequence of the existence of residual interconnected hydrogen bonds which were not completely destroyed during the synthesis stage. The presence of those bonds suggests that reaction time is an important factor in the synthesis of pure $\mathrm{CuO}$ crystals.

The large broadening of the diffraction peaks suggests a very small size of the coherently diffracting domains. Quantitative microstructure analysis was performed using the Whole Powder Pattern Modelling approach, which directly connects a physical model for the microstructure with the diffraction pattern, allowing an extraction of microstructure parameters without recurring to arbitrary 
peak shapes to fit each diffraction peak. This is a more realistic alternative to traditional Line Profile Analysis based on the Williamson-Hall or Warren-Averbach methods. As an example, Figure 2 shows the diffraction pattern of CuO-P5 modelled via WPPM; results for the other specimens are analogous. The modelling was done by assuming the presence of a lognormal distribution of spherical domains and numerical distributions; analysis results are condensed in figure 3 and figure 4 .

Although data are quite noisy, the agreement between data and model is rather good, suggesting that the equiaxial shape assumption is correct for the domains investigated here.

In order to validate the presence of a lognormal distribution, the WPPM modelling was done again by considering the size distribution being described by an arbitrary histogram, directly modelled to the experimental data. Figure 4 shows the results to be compared with the corresponding lognormal curves proposed in Figure 3. It can be observed a quite good agreement between the distributions obtained with the lognormal approximation and those obtained here.

Both in the lognormal (analytical) and free histogram (numerical) cases, the mean domain size ranges from $\sim 4 \mathrm{~nm}(\mathrm{CuO}-\mathrm{P} 1)$ to $\sim 8 \mathrm{mn}(\mathrm{CuO}-\mathrm{P} 5)$. A clear correlation between domain size and quantity of water inside the micelles can be observed, consistent with the literature relations between the size of the initial nanoreactors and the size of the final particles (see e.g. [60] and references therein).

The TEM images in (Figure 4) indicate the synthesis of rod-like nanostructures for all conditions investigated here. From the image of the CuO-P3 specimen (Figure 5) it appears that the nanorod-like structure is indeed made up of small spherical particles that have been self- aligned to form rods. This is consistent with earlier explanation of the directional growth of $\mathrm{CuO}$ nanocrystals along the axis. The size obtained by X-ray diffraction is consistent with the size of the nanoparticles forming the rod-like structures: this is an indication that particles are aligned along the rods but have no crystallographic relationship (i.e. a proper epitaxy did not occur).

\subsection{FTIR spectroscopy}

FTIR spectroscopy (Figure 6) has been used to validate the results of the XRD line profile 
analysis (cf. Figure 1) and to further check the purity of the prepared $\mathrm{CuO}$ nanocrystals. The band at $425 \mathrm{~cm}^{-1}$ can be assigned to the $\mathrm{Cu}-\mathrm{OH}$ stretching mode of residual $\mathrm{Cu}(\mathrm{OH})_{2}$ [61] which could be hidden in the tails of the diffraction patterns. The absorption peaks at around $418 \mathrm{~cm}^{-1}, 536 \mathrm{~cm}^{-1}$ and $590 \mathrm{~cm}^{-1}$ are due to stretching of the $\mathrm{Cu}-\mathrm{O}$ bond along the [101] direction [62-64]. The peak at ca. $1632 \mathrm{~cm}^{-1}$ is due to the bending vibrations of physically adsorbed water [65] whereas the signature of an $\mathrm{OH}$ in-plane bending is at $1257 \mathrm{~cm}^{-1}$.

The peak at $1440 \mathrm{~cm}^{-1}$ is attributed to $\mathrm{CH}_{2}$ in-plane bending while that at $725 \mathrm{~cm}^{-1}$ is due to $\mathrm{CH}_{2}$ in-plane rocking. The broad band between $1200 \mathrm{~cm}^{-1}$ and $1080 \mathrm{~cm}^{-1}$ is due stretching of the C-O bond coordinated to metal cations [66] (Polyoxyethylene bond, present in the head group of Brij 30) and the peak around $668 \mathrm{~cm}^{-1}$ is the bending of $\mathrm{CO}_{2}$. All those signals are a clear signature of the residual presence of the Brij 30 surfactant. The two peaks located around $2851 \mathrm{~cm}^{-1}$ and $2921 \mathrm{~cm}^{-1}$ are attributed to the $\mathrm{CH}_{2}$ symmetric stretching and $\mathrm{CH}_{2}$ asymmetric stretching modes respectively. The shift in position towards higher values $\left(2785 \mathrm{~cm}^{-1}\right.$ and $\left.2850 \mathrm{~cm}^{-1}\right)$ could be attributed to the size effect of the particles, whereas the strong presence the O-H stretching band around $3500-3200 \mathrm{~cm}^{-1}$ is mainly due to water and ethanol residues.

\subsection{UV-Visible-NIR spectroscopy}

Ultraviolet, Visible and Near InfraRed (UV-Vis-NIR) absorption spectroscopy is one of the most widely used techniques to reveal the energy structures and optical properties of a semiconductor. The room temperature spectroscopy of the as-prepared $\mathrm{CuO}$ nanoparticles dispersed in pure ethanol allowed us to investigate the excitonic transitions and optical absorption properties of the material. The spectrum is presented in Figure 7a. Though the spectrum seems featureless, there is observable absorption peak centred at about $350 \mathrm{~nm}$ and $400 \mathrm{~nm}$. The seemingly featureless nature of the spectrum could be due to increasing scattering by the dispersed particles.

To better understand the optical and electronic properties of the prepared nanocrystal, the study and estimation of the mean value of the energy bandgap is of paramount importance. Following the classical Tauc approach, the energy band gap of the $\mathrm{CuO}$ nanocrystals can be estimated according to 
the equations $[67,68]$;

$$
\begin{aligned}
& \alpha E_{p}=k\left(E_{p}-E_{g}\right)^{n} \\
& \alpha h v=k \sqrt{h v-E_{g}}
\end{aligned}
$$

where $\alpha$ is the absorption coefficient, $\mathrm{Ep}=\mathrm{hv}$ is the incident photon energy, Eg is the optical band gap, $\mathrm{h}$ is Planck constant and $\mathrm{k}$ is a proportionality constant. The exponential $\mathrm{n}$ depends on the type of band-band transition and it goes from $1 / 2$ for a direct bandgap semiconductor, to 2 for an indirect bandgap one. The value of $1 / 2$ is therefore used for $\mathrm{CuO}$.

The bandgap Eg was determined for the various specimens (i.e. increasing $\omega$ values as in Table 1) by extrapolating the straight line of the $(\alpha \mathrm{hv})^{2}$ vs. hv plot to intercept on the horizontal photon energy axis as shown in Figure 7b. The energy band gap of the as prepared $\mathrm{CuO}$ nanocrystals is estimated to be between $2.71 \mathrm{eV}$ and $2.16 \mathrm{eV}$ which is larger than the reported value of bulk $\mathrm{CuO}(\mathrm{Eg}=$ $1.85 \mathrm{eV}$ ) [12]. The increase in the band gap of the $\mathrm{CuO}$ nanocrystals with the decrease in particle size is attributed to a quantum confinement effect [69].A correlation of mean size and energy bandgap with $\omega$ is shown in figure 8.

\section{CONCLUSIONS}

Heptane/water microemulsions stabilised with the non-ionic Brij 30 surfactant were used to produce minimally agglomerated rod-like $\mathrm{CuO}$ nanocrystals. TEM shows that the nanorod-like structures consist of well aligned spherical particles of 4-8 $\mathrm{nm}$ in diameter. This suggests that reactions occurred in the spherical micelles followed by directional growth along the axes. The increase in the water to surfactant molar ratio causes an increase in both the average domain size and in the width of the size distribution. Heating of the microemulsion is the key to synthesise $\mathrm{CuO}$ nanocrystals with a well defined morphology.

\section{ACKNOWLEDGEMENTS}

We acknowledge Prof. Stefano Giannella, Dr. Valeria Tagliazucca and Mr. Enrico Moser for assistance in TEM and spectroscopy investigations 


\section{REFERENCES}

[1] A.M. Morales, C. M. Lieber, (1998). Science, 279, 208-211.

[2] G. Fasol, Science, (1996). 272, 1751-1752.

[3] Y. Wu, H. Yan, P. Yang, (2002). Chem. A Eur. J., 8, 1260-1268.

[4] P. Yang, H. Yan, S. Mao, R. Russo, J. Johnson, R. Saykally, N. Morris, J. Phan, R. He, and H. J. Choi, (2002). Adv. Funct. Mater. 12,322.

[5] H. Kamimura, et al (2005). Theory of Copper Oxide Superconductors, Springer-Verlag, Berlin Heidelberg.

[6] J. Bednorz and K. Muller, (1988). Rev. Mod. Phys., 60, 585.

[7] D. Hana, H. Yang, C. Zhu and F. Wang, (2008). Powder Technology, 185, [3], 286-290.

[8] L. de’Medici, X. Wang, M. Capone and A. J. Millis, (2009). Phys. Rev., B, 80, 54501.

[9] E V Antipov, A M Abakumov, (2008). Phys. Usp., 51, 180.

[10] J. Wang, S. He, Z. Li, X. Jing, M. Zhang, Z. Jiang (2009). Colloid Polym. Sci., 287, 853-858.

[11] G Papadimitropoulos, N Vourdas, V EmVamvakas, D Davazoglou, (2005). Journal of Physics: Conference Series, 10, 182-185.

[12] H. Wang, J. Z. Xu, J. J. Zhu, H. Y Chen, (2002). J. Cryst. Growth, 244, 88.

[13] E. Vigil, B. González, I. Zumeta, C. Domingo, X. Doménech, J. Ayllón, (2005). Thin Solid Films, 489, 50.

[14] A. Sambandam, W. Xiaogang, and Y. Shihe, (2005). Materials Chemistry and Physics, 93, [1], $35-40$.

[15] A. Chowdhuri, V. Gupta, K. Sreenivas, R. Kumar, S. Mozumdar, P. Patanjali, (2004). Appl. Phys. Lett., 884, 1180.

[16] J. Chen, S. Deng, N. Xu, W. Zhang, X. Wen, S. Yang. (2003). Appl.Phys. Lett., 83, 746.

[17] X. Gao, J. Bao, G. Pan, H. Zhu, P. Huang, F. Wu, D. Song., (2004). J.Phys. Chem. B., 108, 5547.

[18] W. Siemons, G. Koster, D. H. A. Blank, R. H. Hammond, T. H. Geballe, and M. R. Beasley, (2009). Phys. Rev. B, 79,(19),195122. 
[19] W. A. Harrison, (2007). Phys. Rev. B, 76, 054417.

[20] L. F. Mattheiss, (1972). Phys. Rev. B, 5, 290.

[21] K. Terakura, T. Oguchi, A. R. Williams, and J. Kübler, (1984). Phys.Rev. B, 30, 4734.

[22] J. Zaanen and G. A. Sawatzky, (1985). Phys. Rev. Lett., 55, 418-421.

[23] X. G. Zheng, C. N. Xu, Y. Tomokiyo, E. Tanaka, H. Yamada and Y. Soejima, (2000). Phys. Rev. Lett., 85, 5170.

[24] D. Prabhakaran, C. Subramanian, S. Balakumar and P. Ramasamy, (1999). Physica C, 319, 99.

[25] X. Song, H. Yu, S. Sun, (2006). J. Colloid Interf. Sci., 289, 588.

[26] W. Jisen, Y. Jinkai, S. Jinquan, B. Ying, (2004). Mater. Des., 25, 625.

[27] M. Kaur, K.P. Muthe, S.K. Despande, S. Choudhury, J.B. Singh, N. Verma, S.K. Gupta, J.V. Yakhmi, (2006). J. Cryst. Growth, 289, 670.

[28] C.L. Zhu, C.N. Chen, L.Y. Hao, Y. Hu, Z.Y. Chen, (2004). J. Cryst. Growth, 263, 473.

[29] J. Rockenberger, E C Scher and A P Alivisatos, (1999). J. Am. Chem. Soc., 121, 11595-11596.

[30] L. Wang, G. Cheng, X. Jiang, S. Wang, X. Zhang, and Z. Du, (2009). Appl. Phys. Lett., 95, 083107.

[31] R V Kumar, Y. Diamant and A. Gendanken, (2000). Chem. Mater. 12, 2301.

[32] D. Barreca, E. Comini, A. Gasparotto, C. Maccato, C. Sadad, G. Sberveglieri and E. Tondello(2009). Sensors and Actuators B: Chemical, 141, [1], 270-275.

[33] Z-S Hong, Y. Cao and J-F. Deng, (2002). Mater. Lett., 5234.

[34] M.A. Dar, Q. Ahsanulhaq, Y.S. Kim , J.M. Sohn , W.B. Kim , H.S. Shin, (2009). Applied Surface Science, 2556, 279-6284.

[35] C. Carel, M .Mouallem-Bahout and J.C Gaude, (1999). Solid State Ion., 117, 47.

[36] C.T. Hsieh, J.M. Chen, H.H. Lin, H.C. Shih, (2003). Appl. Phys. Lett., 82, 3316.

[37] B. Liu, H.C. Zeng, (2004). J. Am. Chem. Soc., 126, 16744.

[38] Y. Xu, D. Chen, X. Jiao, (2005). J. Phys. Chem. B, 109, 13561.

[39] P. Scherrer, (1918). Math.-Phys., Kl, $2,98$.

[40] G.K. Williamson, W.H. Hall, (1953). Acta Metall., 1, 22-31. 
[41] J. Solla-Gullòn, V. Montiel, A. Aldaz, and J. Clavilier, (2003). Journal of The Electrochemical Society, 150 (2) E104-E109

[42] C. Tojo, M. C. Blanco, F. Rivadulla, and M. A. Lopez-Quintela, (1997). Langmuir, 13, 19701977

[43] M. M. Bruno , G. A. Planes , M. C. Miras , C. A. Barbero , E. P. Tejera and J. L. Rodríguez, (2010). Molecular Crystals and Liquid Crystals, 521:1, 229-236.

[44] P. Scardi and M. Leoni, (2002). Acta Cryst., A58, 190-200.

[45] M. Leoni, T. Confente, and P. Scardi, (2006). Z. Kristallogr. Suppl., 23, 249.

[46] J.P. Cline, R. D. Deslattes, J.-L. Staudenmann, E. G. Kessler, L.T. Hudson, A. Hennins, and R. W. Cheary, (2000). "NIST Certificate, (SRM 660a) Line Position and Line Shape Standard for Power Diffraction", Gaithersburg USA, NIST Standard Reference Materials Program, NIST, USA

[47] G. Caglioti, A. Paoletti and F.P. Ricci, (1958). Nucl. Instr. and Meth., 3,223.

[48] W.J. Li, E.W. Shi, W.Z. Zhong, Z.W. Yin, (1999). J. Cryst. Growth, 203,186.

[49] W.J. Li, E.W. Shi, W.Z. Zhong, Y.Q. Zheng, Z.W. Yin, (1999). J. Chin. Ceram. Soc., 27, 164.

[50] W.Z. Zhong, G.Z. Liu, E.W. Shi, S.K. Hua, D.Y. Tang, Q.L. Zhao, (1997). J Chin Ceram Soc China, 25, 223-229.

[51] E.W. Shi, W.Z. Zhong, S.K. Hua, R.L. Yuan, B.G. Wang, C.T. Xia, W.J. Li, (1998). Sci. Chin. Ser. E, 28, 37-45.

[52] X. Zhang, Y. Xie, F. Xu, X.H. Liu, D. Xu, (2003). Inorg. Chem. Commun., 6, 1390-1392.

[53] H. Cano, N. Gabas, J.P. Canselier, (2001). J. Cryst. Growth, 224, 335.

[54] Z. Zhou, Q. Zhang, (2006). Chin. J. Spectrosc. Lab., 23, 212-215.

[55] Y.G. Sun, Y.N. Xia, (2002). Adv. Mater., 14, 833-837.

[56] H.R. Oswald, A. Reiler, H.W. Schmalle, and F. Dubler, (1990). Acta Crystallogr., Sect. C, 46, 2279.

[57] H. Weller, H. M. Schmidt, U. Koch, A. Fojtik, S. Baral, A. Henglein, W. Kunath and, K. Weiss, E. Dieman , (1986). Chem. Phys. Lett., 124, 557-560. 
[58] A. Manna, T. Imae, T. Yogo, K. Aoi, M. Okazaki, (2002). J. Colloid and Interface Sci., 256, 297.

[59] S.Quintillán, C. Tojo, M.C. Blanco, M.A. López-Quintela, (2001). Langmuir, 17, 7251-7254.

[60] J. Solla Gullon, (2003). "Characterizacion y comportamiento electroquimico de nanoparticulas metalicas preparadas en microemulsion". Universidad de Alicante.

[61] R. A. Nyquist, R. O Kagel, (1971). "Infrared spectra of inorganic compounds".1st ed., Academic Press, New York and London, 220.

[62] G. F Zou, H Li, D.Zhang, W.; Xiong, K.; Dong, C.; Y. T Qian. (2006). J. Phys. Chem. B, 110, 1632.

[63] K. Kliche, Z. V Popovic, (1990). Phys. Rev. B, 42, 10060.

[64] B. Balamurunga, B.R. Mehta, (2001). Thin Solid Films, 396, 90-96.

[65] A.S. Arico, V.Baglio, A. Di Blasi, V. Antonucci, (2003). Electrochemical communications, 5, $862-866$

[66] A. Bernson, J. Lindgren, W. Huang, R. Frech, (1995). Polymer, 36, 4471.

[67] T.S. Moss, (1959). Optical Properties of Semiconductors, Butterworth, London.

[68] S Tsunekawa, T Fukuda, A Kasuya, (2000). J. Appl. Phys., 87, 1318.

[69] J. P Yang, F. C Meldrum, J. H Fendler, (1995). J. Phys. Chem., 99, 5500. 


\section{Tables}

Table.1. Synthesis conditions and average size of as-produced $\mathrm{CuO}$ nanocrystals

\begin{tabular}{cccccccccc}
\hline Sample & \multicolumn{2}{c}{ Brij30 $^{\circledR}$} & \multicolumn{2}{c}{ n-Heptane } & $\mathrm{CuCl}_{2}$ & $\mathrm{NaOH}$ & $\mathrm{H}_{2} \mathrm{O}$ & $\omega$ & $<\mathrm{D}>$ \\
\cline { 2 - 11 } & \multicolumn{7}{c}{ equiv. } & \multicolumn{7}{c}{ equiv. } & & & $\%$ & & $\mathrm{~nm}$ \\
$\mathrm{~g}$ & $\mathrm{ml}$ & $\mathrm{g}$ & $\mathrm{ml}$ & $\mathrm{mg}$ & $\mathrm{mg}$ & & & \\
$\mathrm{CuO}-\mathrm{P} 1$ & 3.144 & 3.31 & 11.216 & 16.49 & 24.0 & 50.0 & 1.0 & 1.3 & $4.0(0)$ \\
$\mathrm{CuO}-\mathrm{P} 2$ & 3.145 & 3.31 & 11.075 & 16.29 & 25.0 & 50.0 & 2.0 & 2.6 & $4.5(2)$ \\
$\mathrm{CuO}-\mathrm{P} 3$ & 3.143 & 3.31 & 10.946 & 16.10 & 25.0 & 51.0 & 3.0 & 3.8 & $7.3(2)$ \\
$\mathrm{CuO}-\mathrm{P} 5$ & 3.145 & 3.31 & 10.811 & 15.90 & 26.0 & 52.0 & 4.0 & 5.1 & $7.5(1)$ \\
\hline
\end{tabular}




\section{Figure captions}

Figure 1. XRD patterns of as-synthesized $\mathrm{CuO}$ nanocrystals.

Figure 2. WPPM result. Data (circle), model (line) and difference between the two (residual, line below) for the P5 specimen.

Figure 3. Lognormal distribution of the whole set of specimens investigated here.

Figure 4. TEM images of CuO-P1 to CuO-P5 (a-e) and corresponding Selected Area Electron Diffraction [SAED] (f-j).

Figure 5. Image of CuO-P3 specimen showing rod-like structures of spherical particles.

Figure 6. FTIR spectra of the as-prepared $\mathrm{CuO}$ nanocrystals.

Figure 7a. UV-Vis Spectra for the set of specimens analysed here.

Figure 7b. Plots of $(\alpha h v)^{2}$ vs. hv for the $\mathrm{CuO}$ specimens analysed here.

Figure 8. Correlation of mean domain size and optical energy bandgap with $\omega$ for the $\mathrm{CuO}$ specimens. 


\section{Figures}

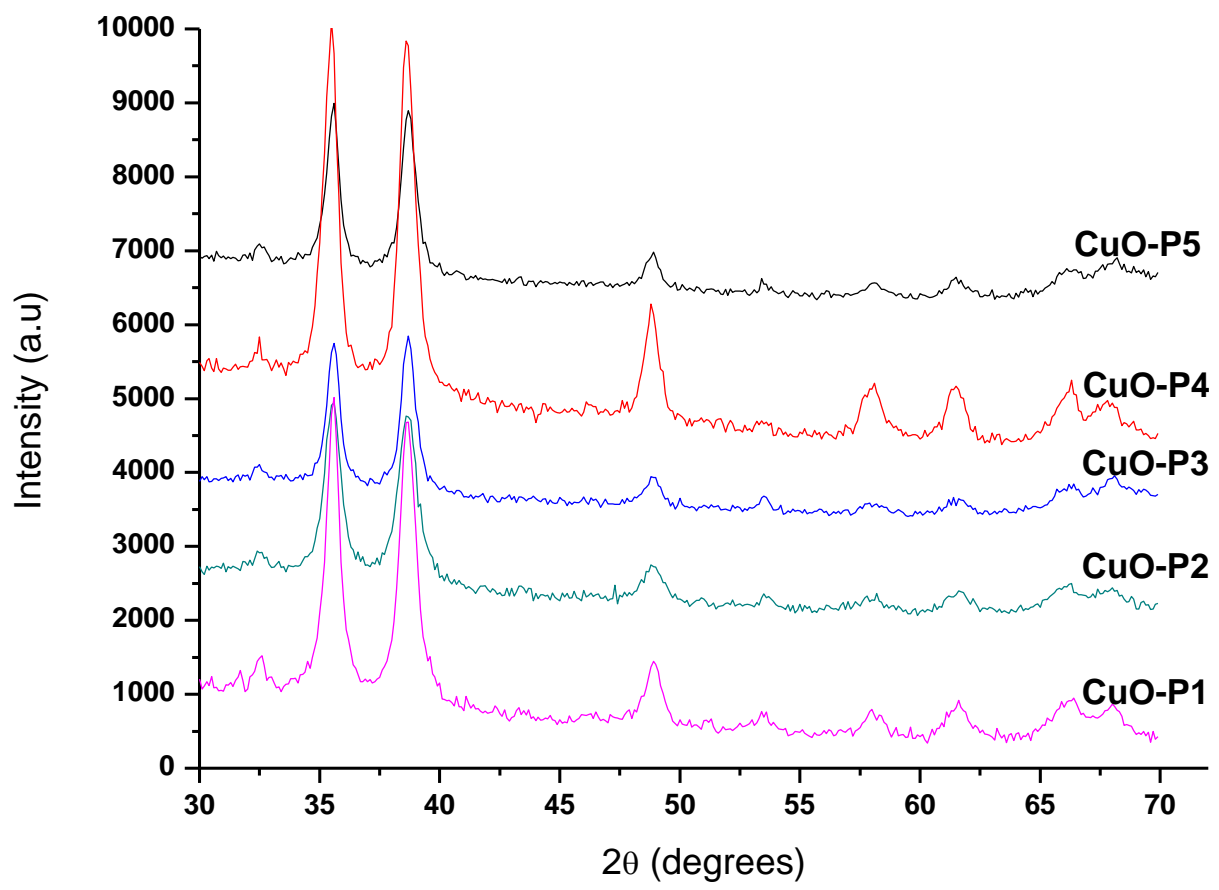

Figure 1.

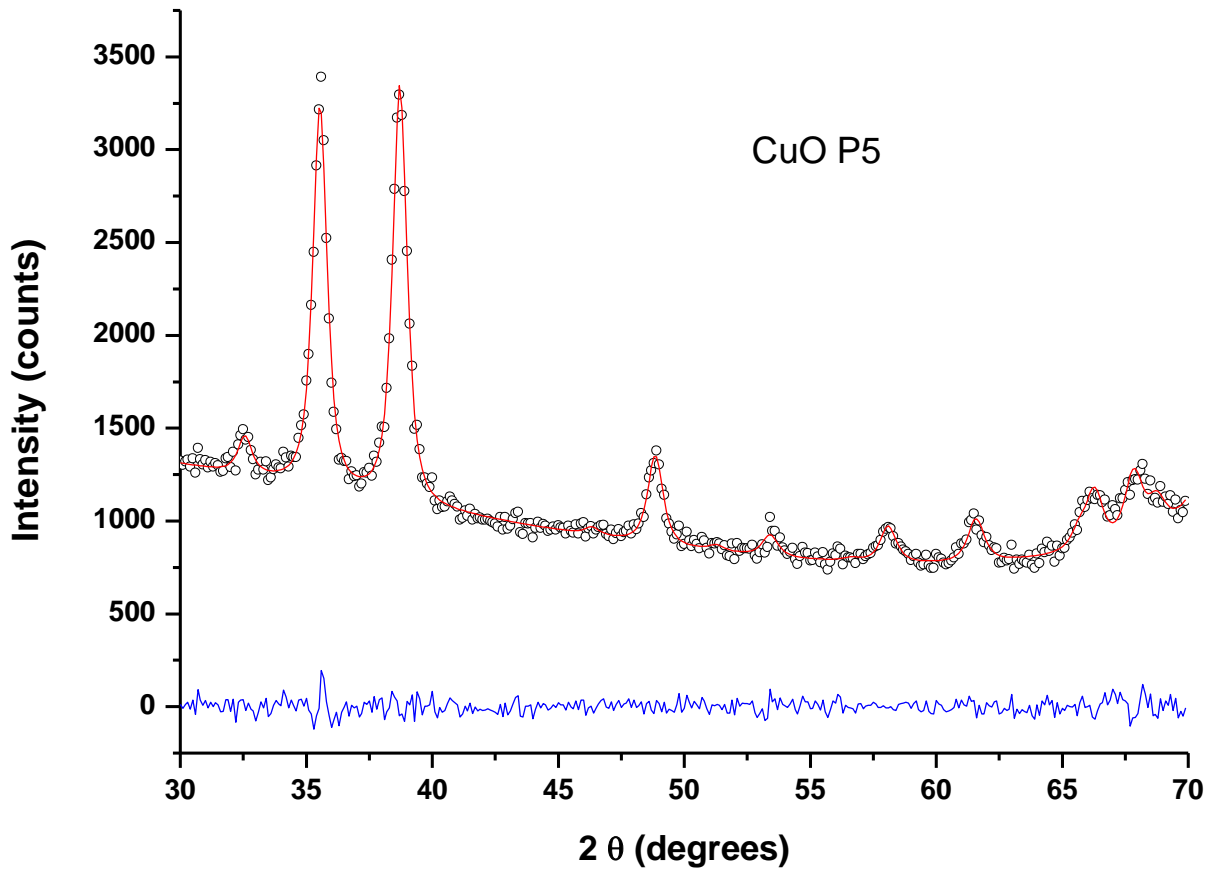


Figure 2 .

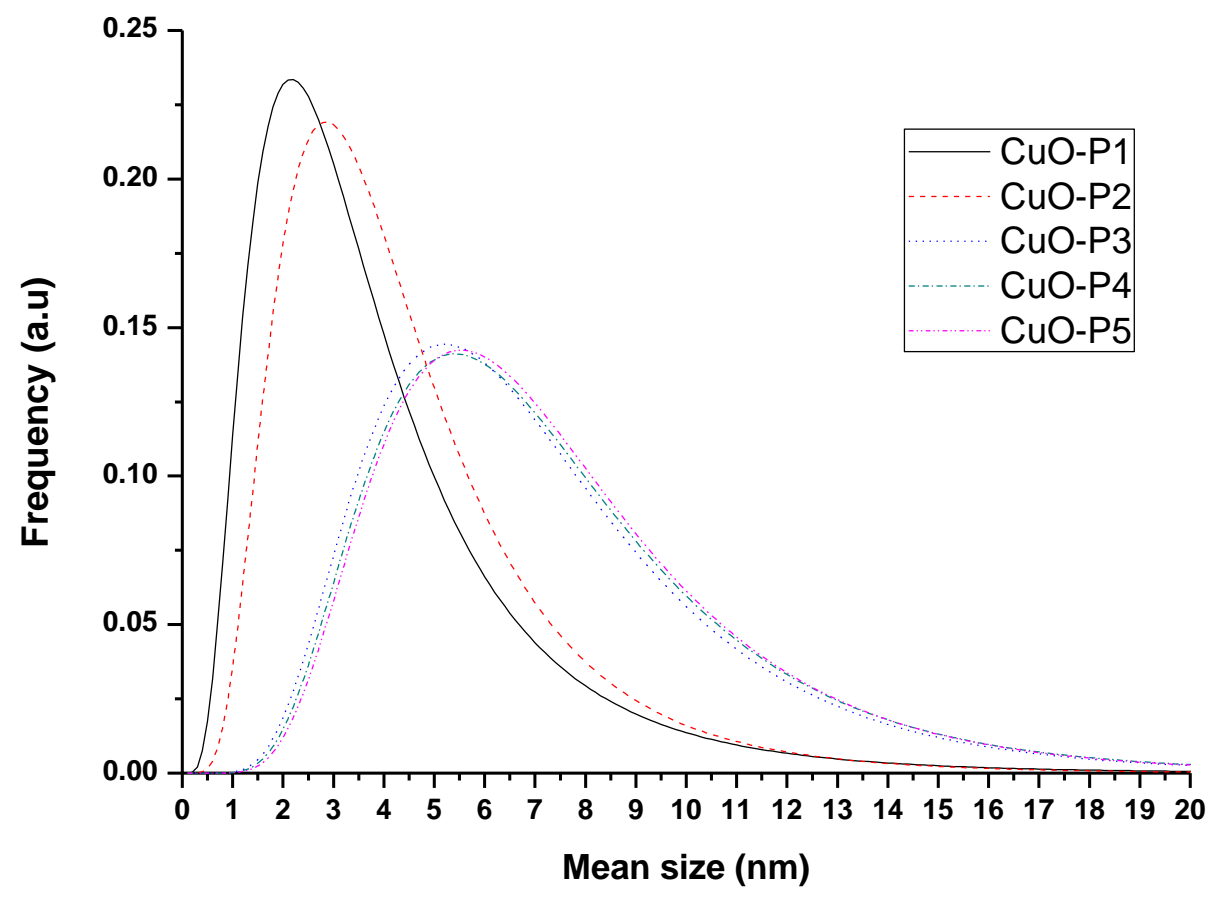

Figure 3.

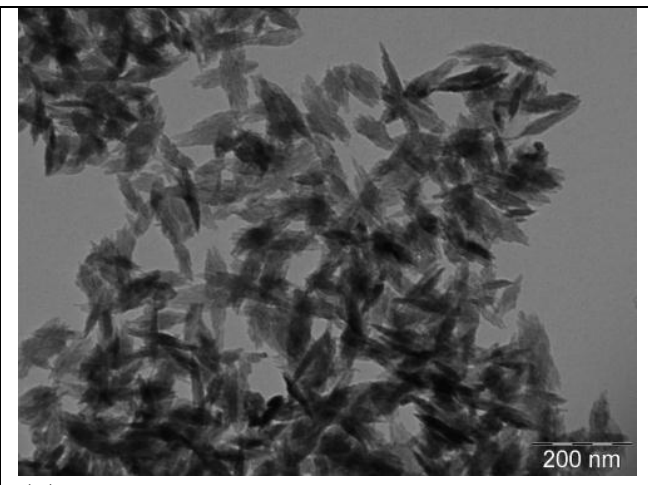

(a)

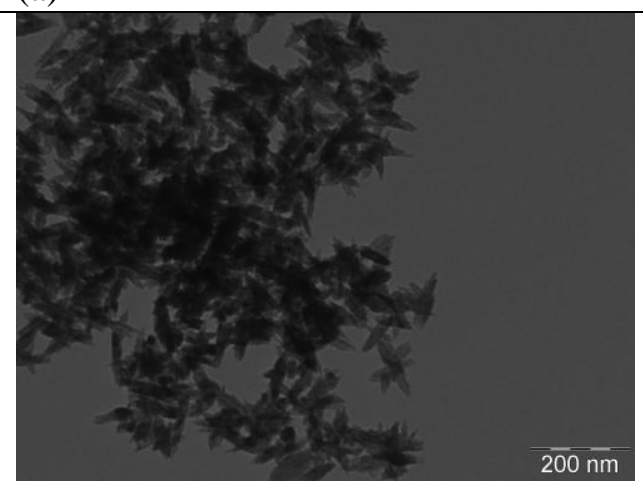

(b)

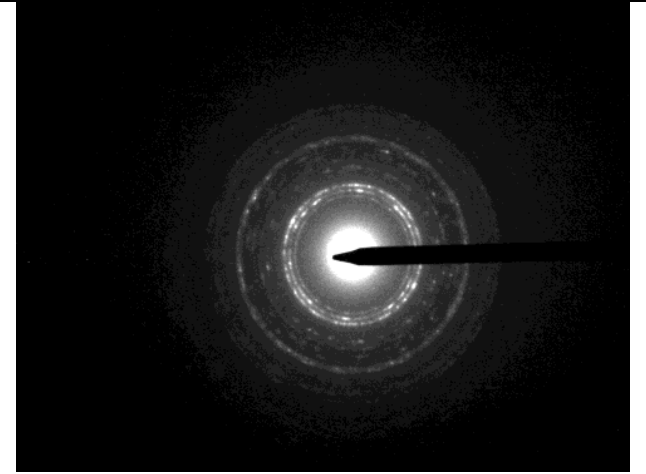

(f)

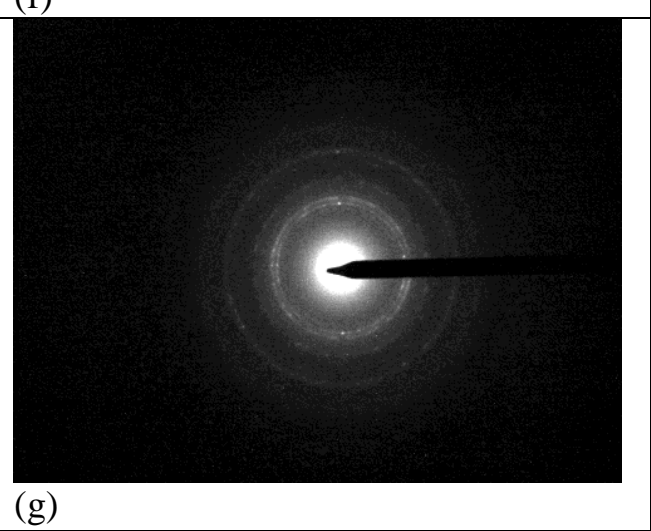




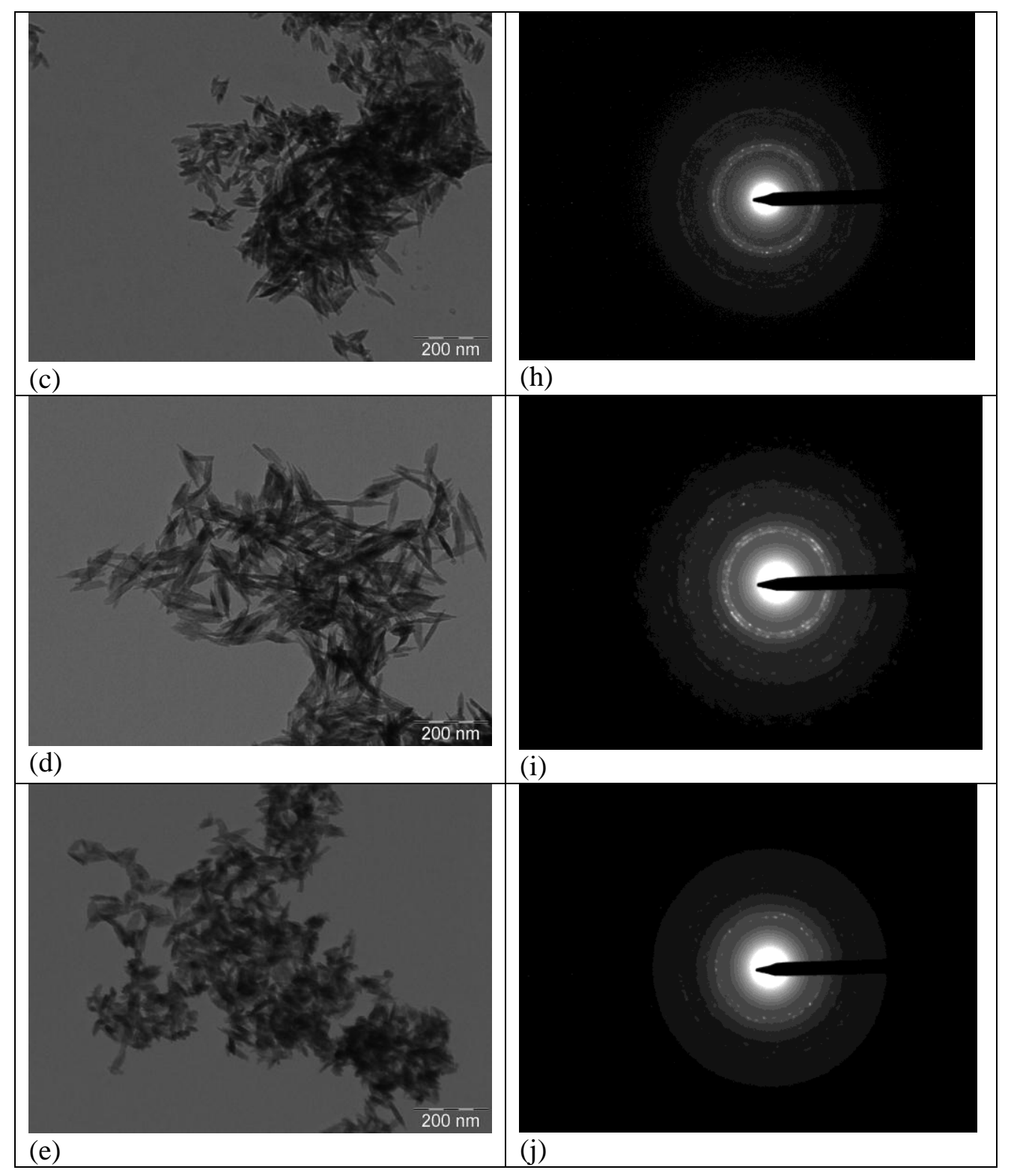

Figure 4. 


\section{$50 \mathrm{~nm}$}

Figure 5.

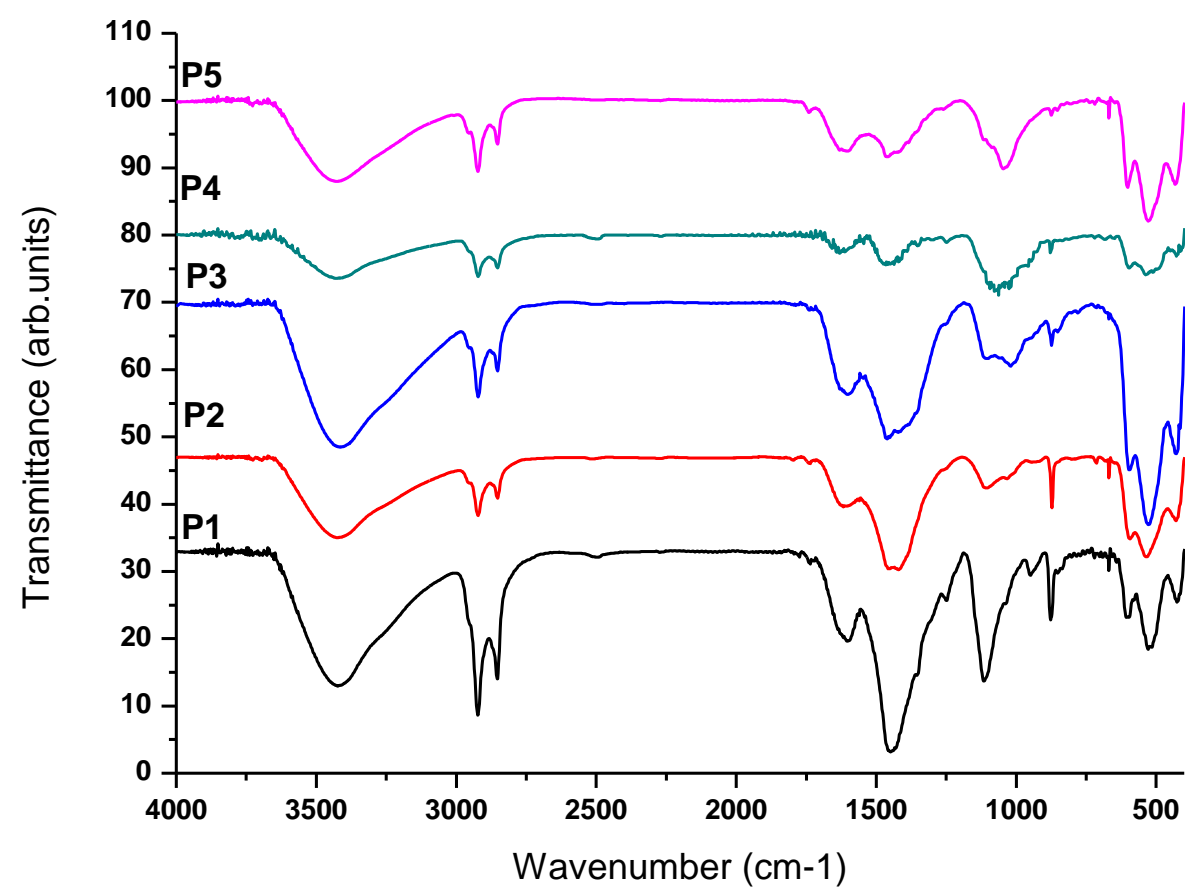

Figure 6. 


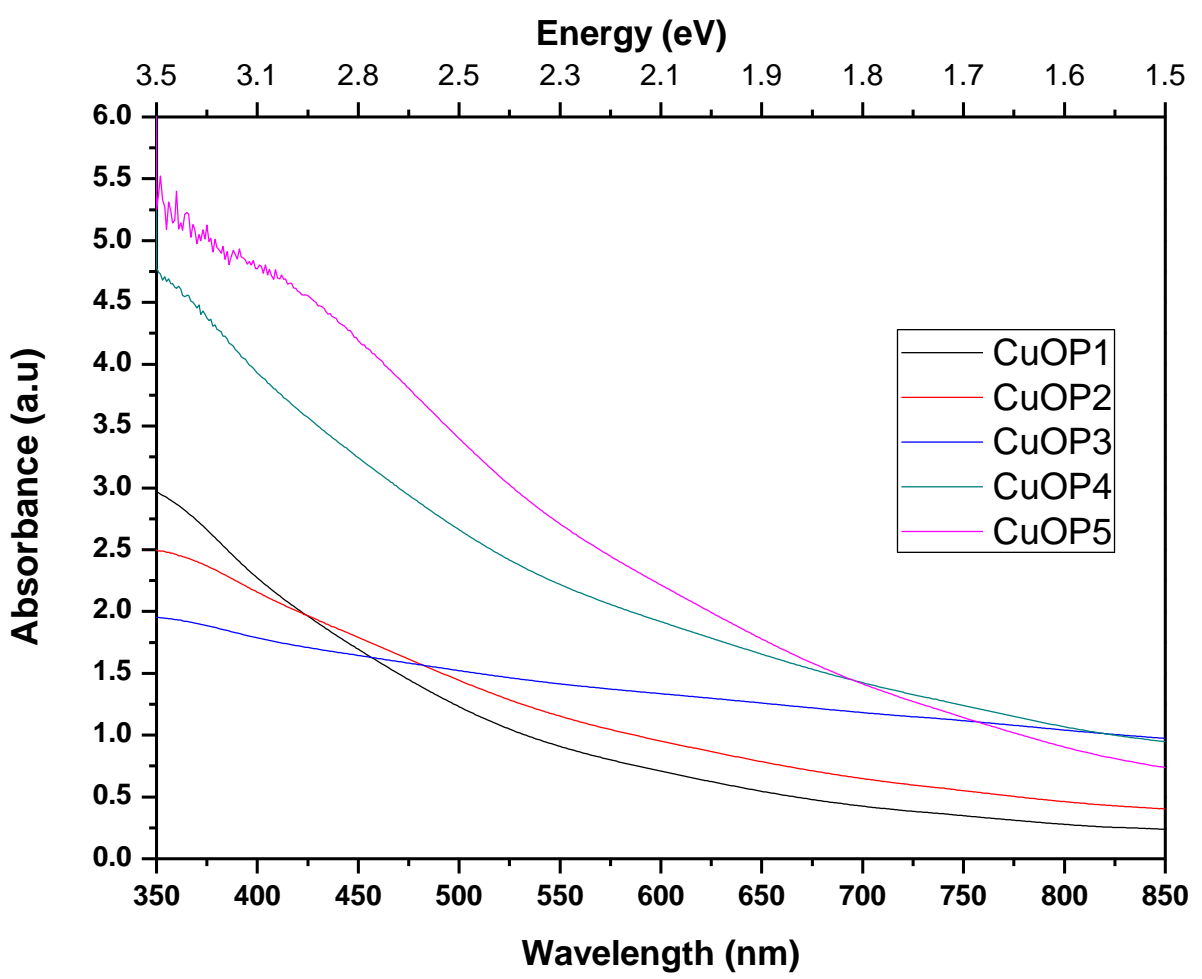

Figure 7a. 


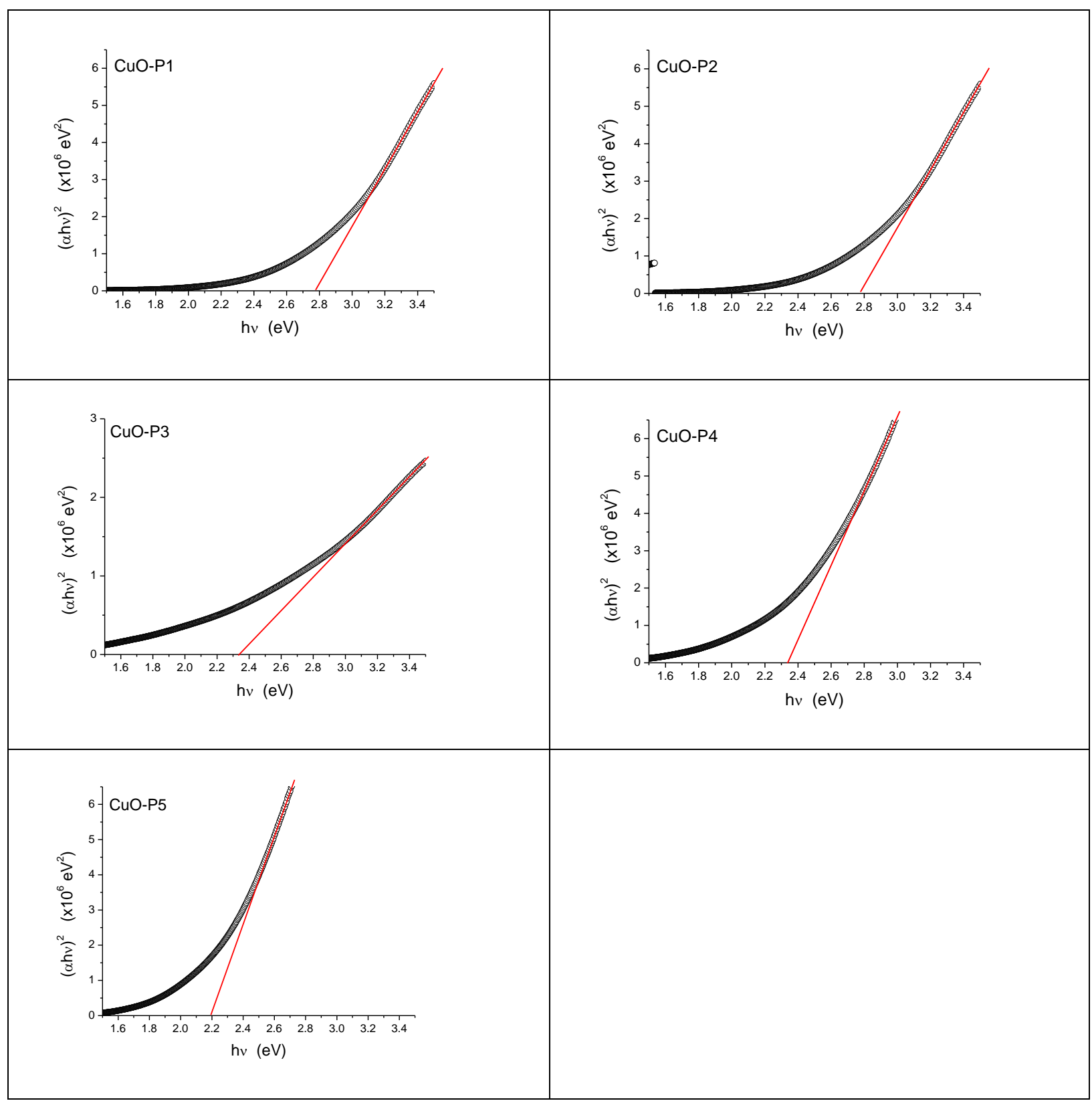

Figure $7 b$. 


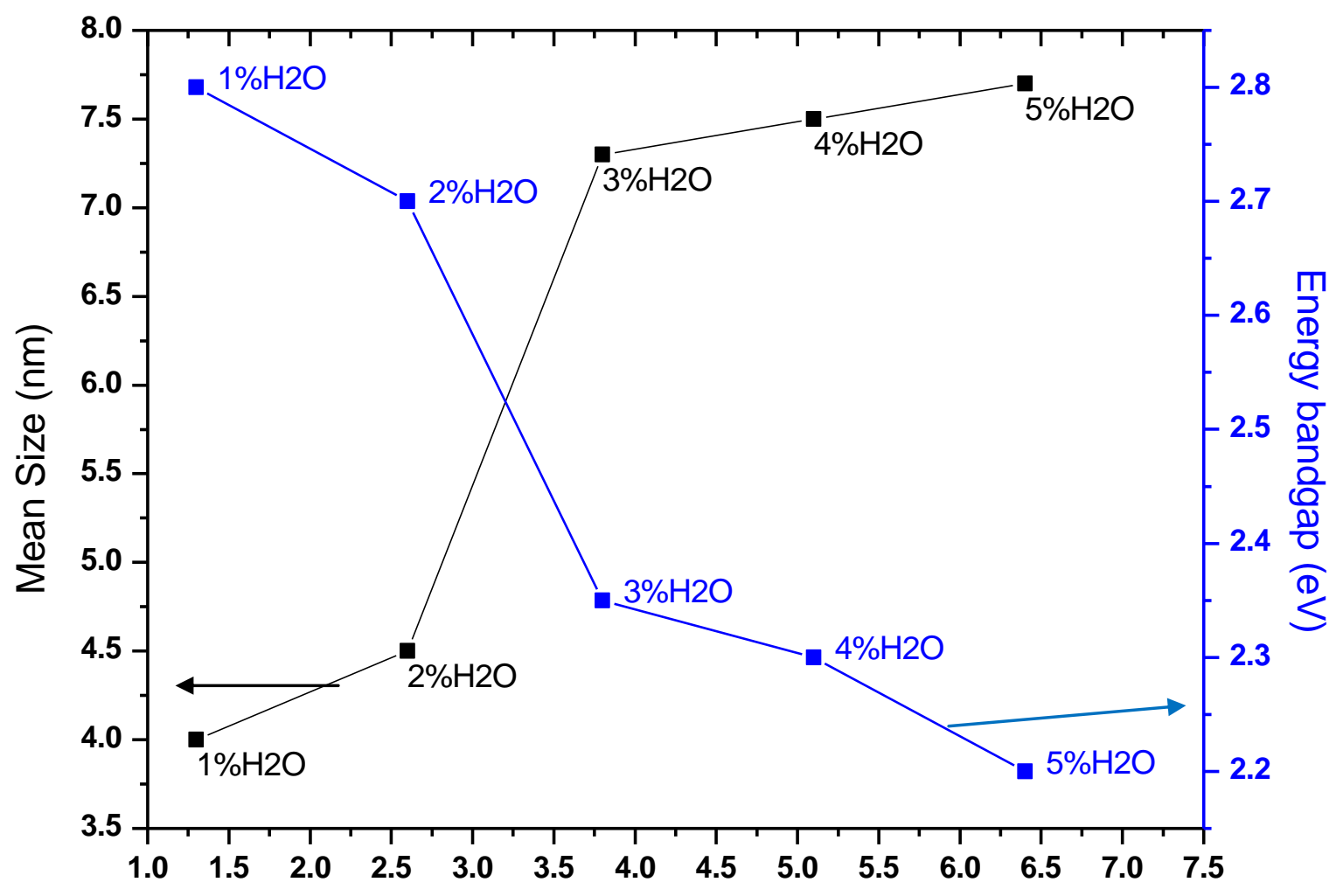

$\omega$

Figure 8 . 